\title{
sciendo
}

DOI 10.2478/sbe-2020-0044

SBE no. 15(3) 2020

\section{INTERPLAYS BETWEEN CORPORATE REPUTATION AND MEDIA - A BIBLIOMETRIC ANALYSIS}

\author{
LUNGULEAC-BARDASUC LEILA \\ Malaga University, Spain \\ BUDAC CAMELIA \\ Lucian Blaga University of Sibiu, Romania \\ OGREAN CLAUDIA \\ Lucian Blaga University of Sibiu, Romania
}

\begin{abstract}
:
As strategic asset - determinant of sustained competitiveness - corporate/firm reputation has a very distinctive feature that sets it apart: although reflection of (better, worse or not at all performed) reputation management at a company's level, it is rather a "representation" / "perception" - built on a business's previous behaviors, but more precisely on the ways its different stakeholders have interacted (acknowledged, internalized, resonated) with them - in a (sometimes unconscious) process highly mediated and moderated by the media. Thus, the current study aims to explore the interplays between corporate/firm reputation and media as they are reflected in the scientific literature - through a bibliometric analysis of the WoS Core Collection database records (between 1992 and 2019), using the VOSviewer tool. With its emphasis on corporate/firm reputation and media, the paper shapes the broad theoretical backgrounds in anticipation of future research and empirical results to be revealed on a much more focused and applied/practical area, namely the reputation of the media in Romania.
\end{abstract}

Key words: corporate/firm reputation, media, bibliometric analysis, WoS Core Collection, vosviewer

\section{Introduction}

Broadly defined as "the opinion that people have of someone or something, based on past behavior or character" (https://dictionary.cambridge.org/), reputation actually represents a strategic intangible asset (Rindova, \& Martins, 2012; Adeosun, \& Ganiyu, 2013; Osiyevskyy, 2017) for any entity (either individual or institutional), determinant of their competitive advantage (or disadvantage) on a given market. Thus, businesses' continuous search for (sustained) competitive advantage, coupled with the fact that reputation is quite hardly (and time consuming) to build while rapidly to (be) destroy(ed), make corporate/firm reputation a moving target and a benchmark of (organizational) 
success - which is disparately reflected on/by media (in all of its forms) at a first glance, then comparatively captured and displayed in different international rankings (e.g. RepTrak, and Fortune), at a second layer of analysis; but eventually, corporate/firm reputation is - more or less distinguishable as regards its contribution, depending on the ways companies are addressing their visible or not so visible reputation related challenges - encapsulated in the businesses' bottom line (Clive, 1997; Duhé, 2009; Gatzert, 2015).

Reputation's highly volatile character against the increasing power of media (of any kind) and, somehow consequently, of the "people" - having, theoretically, more access to information, but in reality being overwhelmed by the amount of available information, and therefore forced to make decisions based on bounded rationality at the best (not to mention their propensity towards emotional choices) - gives a powerful reason to investigate more the relationships and dynamics between corporate/firm reputation and media (together with their determinants and consequences), on the one hand, and on the other hand, the reputation of media, considered as particular/distinctive industry/business (but one that also can significantly impact the reputation of the other businesses/industries).

Within this framework, the current study aims to extensively explore the interplays between corporate/firm reputation and media as they are reflected in the scientific literature; thus, a bibliometric analysis was performed - built on the 453 records retuned by the WoS Core Collection database for the topic "Media AND <<Corporate Reputation>> OR <<Firm Reputation>> (between 1992 - the first year a publication has mentioned media in relation to firm/corporate reputation - and 2019).

\section{Corporate Reputation - Concept and Global Benchmarks}

More than twenty years ago, in a seminal paper introducing the inaugural issue of the Corporate Reputation Review, Fombrun and Van Riel (1997) have synthetized the various perspectives/views (economic, strategic, marketing, organizational, sociological, and accounting) leading to the emergence of corporate reputation as field of research, while conceptualizing corporate reputation as the "collective representation of a firm's past actions and results that describes the firm's ability to deliver valued outcomes to multiple stakeholders. It gauges a firm's relative standing both internally with employees and externally with its stakeholders, in both its competitive and institutional environments".

Later on, in search of "meaning and measurement" for corporate reputation (as component of the reputation paradigm), Chun (2005) has concluded that "it is useful to see corporate reputation as the summary view of the perceptions held by all relevant stakeholders of an organization, that is, what customers, employees, suppliers, managers, creditors, media and communities believe the organization stands for, and the associations they make with it. Image and identity can be usefully seen as the main components of reputation". The latter two have to be aligned - by diligences of reputation management to close the possible gaps between an organization's image and its (desired) identity.

More recently, Veh, A., Göbel, M., \& Vogel, R. (2019) have performed "a review of the literature and assessment of the [corporate reputation] concept"; their bibliometric study (in the management and business areas) has led the authors to the following 
conclusions: (a) "corporate reputation research is embedded in a diverse field of research with subject-specific conceptualizations"; (b) the disciplinary origins of corporate reputation research are found "in economics, organizational science, and marketing research", while its theoretical heritage comes from "signaling and game theory, RBV, institutional theory, and stakeholder theory"; (c) "the current research is predominantly empirical, resulting in evermore new empirical results; (...) more theoretically, derived conceptual work could help to advance research on corporate reputation towards integration"; (d) overall, "corporate reputation is still far from being a uniform concept, leading to a variety of - sometimes unsuitable - operationalizations".

Acknowledging (and emphasizing on) the importance of (corporate) reputation, RepTrak (formerly known as Reputation Institute) and Fortune (in partnership with Korn Ferry) annually release their well-known - and highly referred to (by businesses, media, and academia as well) - survey-based rankings of the Most Reputable Companies Worldwide, and World's Most Admired Companies respectively.

Defining "reputation as the emotional connection that stakeholders (...) have with a given company, [...and arguing that...] if stakeholders have a strong emotional connection with a company, they will buy from, invest in, and want to work for that company - [...which are...] all good things for business", RepTrak builds its ranking around seven reputation drivers: products and services, innovation, workplace, governance, citizenship, leadership, and performance (https://www.reptrak.com/). On the other hand, Fortune uses nine attributes of reputation - ability to attract and retain talented people, quality of management, social responsibility to the community and the environment, innovativeness, quality of products or services, wise use of corporate assets, financial soundness, longterm investment value, and effectiveness in doing business globally - aiming to identify the "best-regarded companies" (those "that enjoy the strongest reputations within their industries and across industries") (https://www.kornferry.com/).

A quick comparison between the Top 10 Most Reputable Companies (according to RepTrak) and Top 10 Most Admired Companies (according to Fortune) in 2020 versus 2010 (Table 1) reveals: quite high levels of volatility as concerns a company's reputation (only two companies are in RepTrak's Top 10 both in 2010 and 2020, while four companies are in Fortune's Top 10 both in 2010 and 2020); a diversity of represented industries (from consumer products and entertainment to computer software and financials); an absolute majority of USA headquartered companies in Fortune's Top 10 and a relative one in RepTrak's Top 10.

Table 1. Top 10 Most Reputable Companies and Top 10 Most Admired Companies -2020 versus 2010 -

\begin{tabular}{|l|l|l|l|}
\hline \multicolumn{2}{|c|}{ RepTrak: Top 10 Most Reputable Companies } & \multicolumn{2}{c|}{$\begin{array}{c}\text { Fortune: Top 10 Most Admired } \\
\text { Companies }\end{array}$} \\
\hline \multicolumn{1}{|c|}{2010} & \multicolumn{1}{c|}{2020} & \multicolumn{1}{c|}{2010} & \multicolumn{1}{c|}{} \\
\hline Google & LEGO & Apple & Apple \\
\hline Sony & Walt Disney & Google & Amazon \\
\hline Walt Disney & Rolex & Berkshire Hathaway & Microsoft \\
\hline BMW & Ferrari & Johnson \& Johnson & Walt Disney \\
\hline Daimler (Mercedes-Benz) & Microsoft & Amazon.com & Berkshire Hathaway \\
\hline
\end{tabular}




\begin{tabular}{|l|l|l|l|}
\hline Apple & Levi's & Procter \& Gamble & Starbucks \\
\hline Nokia & Netflix & Toyota Motor & Alphabet \\
\hline IKEA & Adidas & Goldman Sachs & JPMorgan Chase \\
\hline Volkswagen & Bosch & Wal-Mart & Costco Wholesales \\
\hline Intel & Intel & Coca-Cola & Salesforce \\
\hline
\end{tabular}

Source of data: RepTrak (https://www.reptrak.com) and Fortune (https://fortune.com/)

\section{Methodology of the Study}

Aiming to analyze the interplays between corporate/firm reputation and media as they are reflected in the scientific literature, a search for the topic "Media AND <<Corporate Reputation>> OR <<Firm Reputation>>" in WoS Core Collection database has been performed; a total of 453 records (from 1992 - the first year a publication has mentioned media in relation to firm/corporate reputation - and 2019) has been returned and extracted for analysis.

In order to perform the bibliometric analysis, the VOSviewer version 1.6.15 software tool (https://www.vosviewer.com/) was employed. In short, VOSviewer is "a freely available computer program (...) developed for constructing and viewing bibliometric maps; (it uses) the VOS mapping technique (...), where VOS stands for visualization of similarities" (Van Eck \& Waltman, 2010). As, during the recent years, the corpus of scientific works has been enriched in an unprecedented pace, making systematic reviews of existing literature more challenging (in terms of identifying relevant works, theories and/or line of thoughts), the VOSviewer tool has been increasingly use by authors including in areas close to the current endeavor (Kapoor, et al., 2018; Li, Spry, \& Woodall, 2020; Gomez-Trujillo, Velez-Ocampo, \& Gonzalez-Perez, 2020).

Following a brief (quantitative) evaluation of the research in the field of "Media AND <<Corporate Reputation>> OR <<Firm Reputation>>" (based on WoS Analyze Result tool), a more in-depth analysis has been made using the VOSviewer tool - by capitalizing on the maps created on both text and bibliographic data. Once exported to VOSviewer, the results provided by WoS (containing Full Record and Cited References) have become data sources for creating/generating new maps (Van Eck \& Waltman, 2020): text data were used to construct networks of co-occurrence links between terms, while bibliographic data were used to construct networks of co-occurrence of keywords or citation (of sources and documents).

\section{Brief overview of WoS results on "Media AND $<<$ Corporate Reputation $>>$ OR <<Firm Reputation>>"}

Between 1992 and 2019 Web of Science Core Collection gathers a total of 453 results on the topic "Media AND <<Corporate Reputation>> OR <<Firm Reputation>>" (Figure 1). 370 (representing $81.67 \%$ ) of these records belong to the current decade (2011-2019), which documents once more the increasing interest on (and significance of) both corporate/firm reputation and media, as well as the strong (er with time) relationships between the two. 
Figure 1. Number of records for "Media AND $<<$ Corporate Reputation $\gg>$ OR $<<$ Firm Reputation >> in WoS

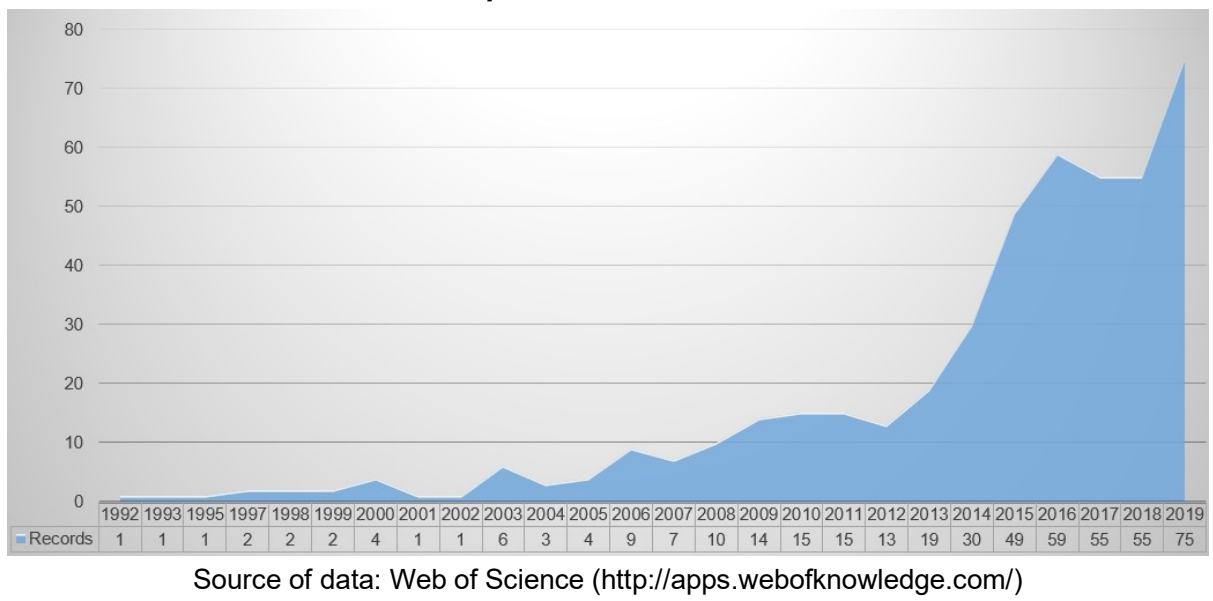

A total of 63 WoS categories are represented when looking for the topic "Media AND <<Corporate Reputation>> OR <<Firm Reputation>>" in WoS; although, the top 10 WoS categories in terms of number of records clearly dominate (Figure 2), with 601 records $(80.13 \%$ of 750 - as some of the results are placed in more than just one WoS category). Business ( 47.9 as \% of 453 ), Management (36.2 as \% of 453 ), Economics (11.47 as \% of 453$)$, and Communication (11.25 as \% of 453$)$ are, by far, the best represented Wos Categories, followed, in Top 10, by Business Finance $(5.07 \%)$, Psychology Applied (4.63\%), Ethics (4.19\%), Computer Science Information Systems (3.97\%), Hospitality Leisure Sport Tourism (3.97\%), and Information Science Library Science $(3.97 \%)$.

Figure 2. WoS Categories for "Media AND $<<$ Corporate Reputation $>>$ OR $<<$ Firm Reputation >"

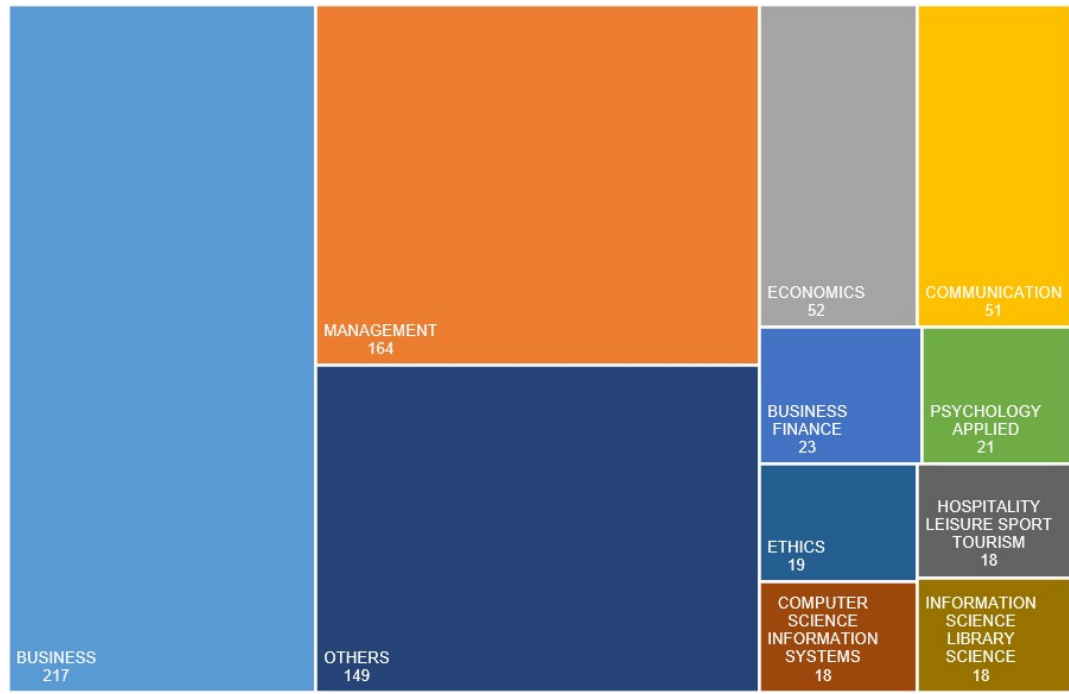

Source of data: Web of Science (http://apps.webofknowledge.com/) 
As regards the Research Areas (Figure 3), Business economics (338 records, representing $74,6 \%$ of 453 ), Communication (51 records, representing $11,3 \%$ of 453 ), and Social Sciences Other Topics (47 records, representing $10.4 \%$ of 453 ) make the top three (Figure 3), while Computer Science (6.6\%), Psychology (5.5\%), Environmental Sciences Ecology (4.6\%), Information Science Library Science (4\%), Science Technology Other Topics (2.9\%), Engineering (2.2\%), and Agriculture (1.8\%) complete the top 10 of WOS Research Areas.

\section{Figure 3. Research Areas in WoS for "Media AND $<<$ Corporate Reputation $>>$ OR $<<$ Firm Reputation >"}

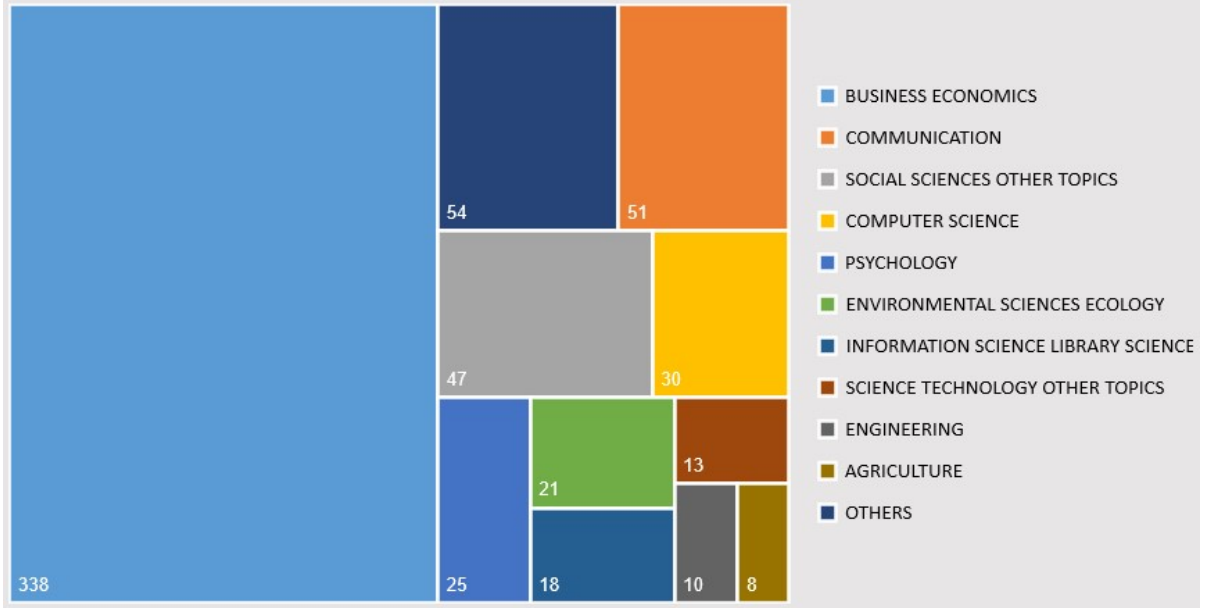

Source of data: Web of Science (http://apps.webofknowledge.com/)

In terms of Document Types: 384 records fall into the Article category, while 48 are classified as Proceedings Paper, and 20 as Review. The Book Chapter category counts 15 records, Early Access gathers 7 results, while both Book Review and Editorial Material are represented by 2 respective records; one Book and one Meeting Abstract complete the classification of documents.

The WoS Core Collection search for "Media AND <<Corporate Reputation>> OR <<Firm Reputation>>" returned 292 Source Titles; Table 2 displays the top 10 source title by number of records - where Journal of Business Ethics, Corporate Reputation Review, and Academy of Management Journal are making the top 3; all the other source titles (that are not in top 10) gather at most 4 records each (under $1 \%$ of 453 ).

Table 2. Top 10 Source Titles in Wos for "Media AND $<<$ Corporate Reputation $>>$ OR $<<$ Firm Reputation >> - by number of records

\begin{tabular}{|c|c|c|}
\hline Source Titles & Records & $\%$ of 453 \\
\hline 1. Journal of Business Ethics & 19 & 4.19 \\
\hline 2. Corporate Reputation Review & 18 & 3.97 \\
\hline 3. Academy of Management Journal & 14 & 3.09 \\
\hline 4. Strategic Management Journal & 12 & 2.64 \\
\hline 5. Public Relations Review & 10 & 2.20 \\
\hline
\end{tabular}


6. Journal of Business Research 1.76

7. Corporate Communications

8. Corporate Reputation and Media. A Neo Institutionalist Analysis on Example of $\mathrm{MA}$

7

9. Schriften Zur Unternehmensentwicklung

6

10. Unternehmensreputation Und Medien Eine Neo Institutionalistische Analyse Am Beispiel Von M A

Source of data: Web of Science (http://apps.webofknowledge.com/)

If considering Organizations, the search returned 557 results: seven USA universities, two Dutch and Singaporean universities respectively and a British one are the best represented ones (making the top 12) by number of records (Table 3 ).

Table 3. Top 10 Organizations in Wos for "Media AND $<<$ Corporate Reputation $>>$ OR $<<$ Firm Reputation>>" - by number of records

\begin{tabular}{|l|l|c|c|c|}
\hline \multicolumn{2}{|l|}{ Organizations } & Country & Records & \% of $\mathbf{4 5 3}$ \\
\hline 1. & Pennsylvania State Univ & USA & 10 & 2.20 \\
\hline 2. & Univ Amsterdam & Netherlands & 9 & 1.98 \\
\hline 3. & Univ Georgia & USA & 8 & 1.76 \\
\hline 4. & Vrije Univ Amsterdam & Netherlands & 7 & 1.54 \\
\hline 5. & Singapore Management Univ & Singapore & 6 & 1.32 \\
\hline 6. & Texas A\&M Univ & USA & 6 & 1.32 \\
\hline 7. & Univ Texas Austin & USA & 6 & 1.32 \\
\hline 8. & Middlesex Univ & England & 5 & 1.10 \\
\hline 9. & Nanyang Technol Univ & Singapore & 5 & 1.10 \\
\hline 10. & Oklahoma State Univ & USA & 5 & 1.10 \\
\hline 11. & Univ Alabama & USA & 5 & 1.10 \\
\hline 12. & Univ South Carolina & USA & 5 & 1.10 \\
\hline
\end{tabular}

Source of data: Web of Science (http://apps.webofknowledge.com/)

\section{Bibliometric analysis of WoS results on "Media AND $\ll$ Corporate Reputation $>>$ OR <<Firm Reputation>>" using VOSviewer software}

Between 1992 and 2019, the "term co-occurrence map based on text data" has eventually generated 88 items (Figure 4) - grouped in 4 clusters, developing 2527 links and a total link strength of 6464 . The results were generated by using binary counting of data from bibliographic database files, ten as the minimum number of occurrences of a term, and after a cleaning of non-relevant items (related, most of them, to the methodological development of the previous studies).

Overall, there are 4 occurrences of "reputation": in cluster 1 - as "firm reputation" and in cluster 3 - in the following constructs: "good reputation", "media reputation", and "organizational reputation". "Media", on the other hand, occurs 3 times, as "media 
coverage" and "social media" - in cluster 2 - and as "media reputation" - in cluster 3 respectively. In detail:

- Cluster 1 (red) - reunites 26 items, "firm" being the most prominent (86 links, 815 total link strength, 173 occurrences)

o other relevant items in cluster 1 (and closely related to "firm"): corporation, financial performance, firm performance, firm reputation, behavior, decision, outcome, change, event, expectation, stakeholder group, CEO, risk;

- connections of "firm" with relevant items from another clusters: crisis, resource, society, sustainability, contribution, employee, job, consumer, engagement, communication, image, performance, $\operatorname{SME}(\mathrm{s})$, social medium, public, competitive advantage, innovation, brand, marketing, knowledge.

- Cluster 2 (green) - reunites 25 items, "social medium" being the most prominent (83 links, 404 total link strength, 68 occurrences)

- other relevant items in cluster 2 (and closely related to "social medium"): internet, social media, media coverage, Facebook, message, communication, corporate communication, engagement, content, crisis, public, user, employer, employee, job, individual, group, attitude;

- connections of "social medium" with relevant items from another clusters: resource, knowledge, environment, review, performance, practitioner, mouth, consumer, marketing, resource, firm, outcome, behavior, risk, knowledge, brand, intention, change.

- Cluster 3 (blue) - reunites 21 items, "environment" being the most prominent (76 links, 209 total link strength, 34 occurrences

- other relevant items in cluster 3 (and closely related to "environment"): interview, work, knowledge, competitive advantage, resource, order, assessment, contribution, good reputation, media reputation, sustainability;

- connections of "environment" with relevant items from another clusters: firm reputation, firm, behavior, risk, employee, social medium, communication, use, image, engagement, brand, consumer, marketing.

- Cluster 4 (yellow) - reunites 16 items, "performance" being the most prominent (75 links, 283 total link strength, 56 occurrences)

o other relevant items in cluster 4 (and closely related to "performance"): innovation, sale, antecedent, review, conceptualization, consumer, brand, marketing, word, mouth, proposition;

- connections of "performance" with relevant items from another clusters: firm, firm reputation, firm performance, behavior, outcome, decision, resource, SME(s), competitive advantage, knowledge, environment, employee, social medium, communication, image, engagement, consumer, sale, review, innovation, sustainability. 
Figure 4. "Media AND <<Corporate Reputation $>>$ OR <<Firm Reputation $>>$ " - term cooccurrence map based on text data

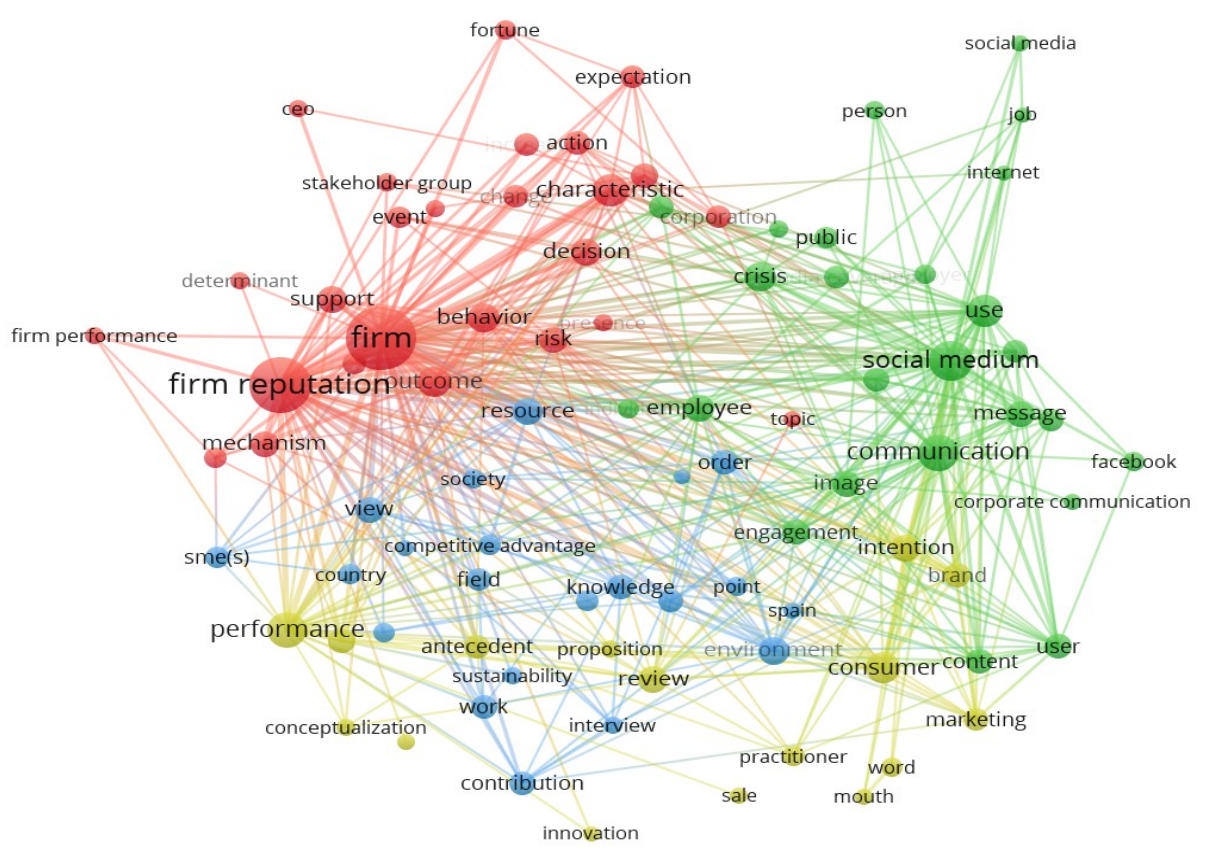

Source: authors - applying VOSviewer tool to WoS Core Collection data

The "keywords co-occurrence map based on bibliographic data" (Figure 5) generated considering five to be the minimum number of occurrences of a keyword and taking into account the first 50 keywords - reveals 4 clusters, 889 links and a total link strength of 3485 . In details:

- Cluster 1 (red) - built around "firm reputation" (item which has: 47 links, a total link strength of 376 , and 107 occurrences) - linked with:

○ items belonging to the same cluster: information, performance, organizational reputation, social responsibility, management, industry, market, organization, communication, construction, responsibility, legitimacy, media;

- items belonging to other clusters: impact, corporate image, corporate reputation, social media, brand, word of mouth, perceptions, commitment, trust, customer satisfaction, quality, reputation, CSR, strategy, firm performance, financial performance, stakeholders, stakeholder value;

- Cluster 2 (green) - developed around "corporate reputation" (item which has: 49 links, a total link strength of 618 , and 172 occurrences) - linked with:

○ items belonging to the same cluster: word of mouth, impact, social media, identity, image, credibility, strategies, perceptions, brand, corporate image;

o items belonging to other clusters: organization, firm reputation, communication, information, responsibility, legitimacy, management, performance, media, market, social construction, social sustainability, industry, organizational reputation, reputation, stakeholders, financial performance, firm 
performance, strategy, stakeholders, stakeholder value, quality, trust, commitment, customer satisfaction;

- Cluster 3 (blue) - developed around "reputation" (item which has: 49 links, a total link strength of 352 , and 87 occurrences) - linked with:

o items belonging to the same cluster: firm, strategy, CSR, sustainability, financial performance, firm performance, stakeholders;

- items belonging to other clusters: corporate reputation, impact, social media, word of mouth, brand, corporate image, identity, impact, trust, satisfaction, customer satisfaction, quality, consequences, model, management, performance, information, legitimacy, organization, organizational reputation, firm reputation, communication, responsibility, market, social construction;

- Cluster 4 (yellow) - developed around "consequences" (item which has: 45 links, a total link strength of 207 , and 38 occurrences) - linked with:

o items belonging to the same cluster: satisfaction, customer satisfaction, trust, antecedents, commitment, quality, model;

○ items belonging to other clusters: Corporate reputation, impact, social media, brand, image, credibility, strategies, perceptions, identity, sustainability, strategy, firm performance, financial performance, CSR, stakeholder value, reputation, stakeholders, framework, performance, organizational reputation, firm reputation, management, communication, legitimacy, market, social responsibility.

Figure 5. "Media AND <<Corporate Reputation >> OR <<Firm Reputation >>" - keywords cooccurrence map based on bibliographic data

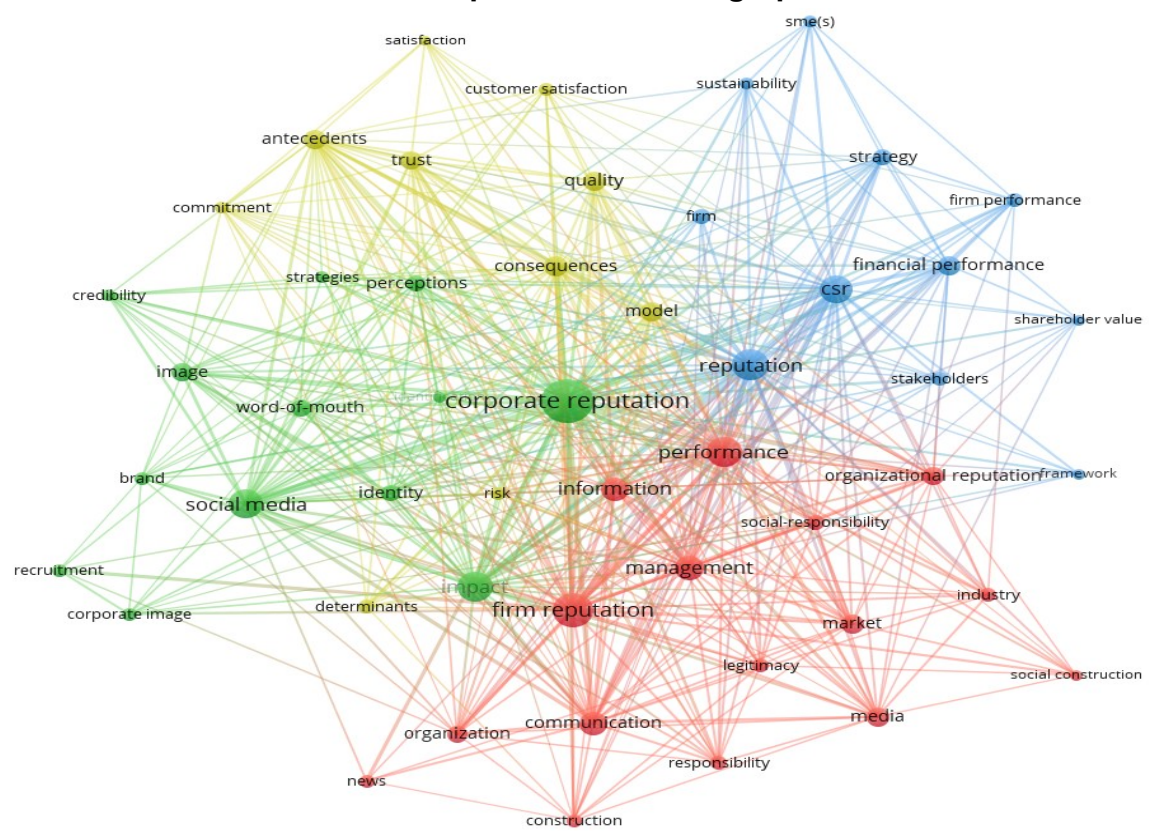

Source: authors - applying VOSviewer tool to WoS Core Collection data 
As concerns citation - with documents as unit of analysis (if considering the $\mathbf{3 0 9}$ connected items and a minimum cluster size of 35 items), 5 clusters have been revealed (Figure 6), the most cited documents per cluster being listed in Table 4 - together with their respective citations and number of links.

Figure 6. "Media AND <<Corporate Reputation >> OR <<Firm Reputation>>" - citation documents map based on bibliographic data

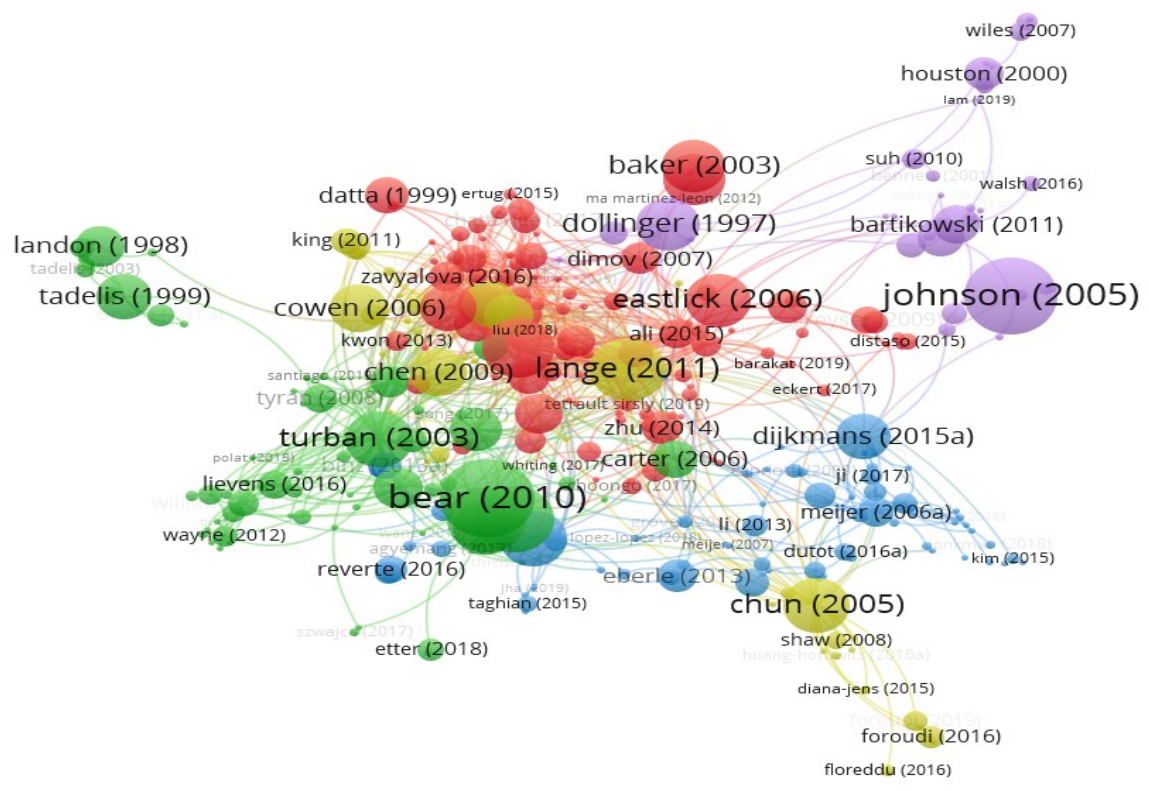

Source: authors - applying VOSviewer tool to WoS Core Collection data

Table 4. "Media AND $<<$ Corporate Reputation $>>$ OR $<<$ Firm Reputation $>>$ " - most cited document per cluster

\begin{tabular}{|c|l|c|c|}
\hline Cluster & Document & Links & Citations \\
\hline 1. & $\begin{array}{l}\text { Pfarrer, M. D., Pollock, T. G., \& Rindova, V. P. (2010). A tale of two assets: } \\
\text { The effects of firm reputation and celebrity on earnings surprises and } \\
\text { investors' reactions. Academy of Management Journal, 53(5), 1131-1152. }\end{array}$ & 66 & 292 \\
\hline 2. & $\begin{array}{l}\text { Bear, S., Rahman, N., \& Post, C. (2010). The impact of board diversity and } \\
\text { gender composition on corporate social responsibility and firm } \\
\text { reputation. Journal of Business Ethics, 97(2), 207-221. }\end{array}$ & 10 & 495 \\
\hline 3. & $\begin{array}{l}\text { Lai, C. S., Chiu, C. J., Yang, C. F., \& Pai, D. C. (2010). The effects of } \\
\text { corporate social responsibility on brand performance: The mediating effect } \\
\text { of industrial brand equity and corporate reputation. Journal of Business } \\
\text { Ethics, 95(3), 457-469. }\end{array}$ & 12 & 255 \\
\hline 4. & $\begin{array}{l}\text { Lange, D., Lee, P. M., \& Dai, Y. (2011). Organizational reputation: A } \\
\text { review. Journal of management, 37(1), 153-184. }\end{array}$ & 75 & 328 \\
\hline 5. & $\begin{array}{l}\text { Johnson, D., \& Grayson, K. (2005). Cognitive and affective trust in service } \\
\text { relationships. Journal of Business Research, 58(4), 500-507. }\end{array}$ & 5 \\
\hline
\end{tabular}

Source: authors - applying VOSviewer tool to WoS Core Collection data

A quick look at the most cited document in each cluster provides significant insights on the main research topics and their results. 
Thus, in Pfarrer, Pollock, \& Rindova (2010), the authors "compare the effects of (...) firm reputation and celebrity on (1) the likelihood that a firm announces a positive or negative earnings surprise, and (2) investors' reactions to these surprises. [...Their findings are...] that firms that have accumulated high levels of reputation (...) are less likely, and firms that have achieved celebrity (...) more likely to announce positive surprises than firms without these assets. Both high-reputation and celebrity firms experience greater market rewards for positive surprises and smaller market penalties for negative surprises than other firms".

Bear, Rahman, \& Post's (2010) article mainly "explores how the diversity of board resources and the number of women on boards affect firms' corporate social responsibility (CSR) ratings, and how, in turn, CSR influences corporate reputation. [...The research finds that...] CSR ratings had a positive impact on reputation and mediated the relationship between the number of women on the board and corporate reputation".

Aiming to investigate "first, the effects of CSR and corporate reputation on industrial brand equity; second, the effects of CSR, corporate reputation, and brand equity on brand performance; and third, the mediating effects of corporate reputation and industrial brand equity on the relationship between CSR and brand performance", Lai et al. (2010) concluded that "CSR and corporate reputation have positive effects on industrial brand equity and brand performance. In addition, corporate reputation and industrial brand equity partially mediate the relationship between CSR and brand performance".

In their review study on organizational reputation, Lange, Lee, \& Dai (2011) "identify three dominant conceptualizations, namely, that reputation consists of familiarity with the organization, beliefs about what to expect from the organization in the future, and impressions about the organization's favorability. (...) The authors [...emphasize on...] the needs to investigate organizational reputation as multidimensional and dynamic and to model its antecedents and effects as more complex than the unidirectional models typically proposed".

Johnson, \& Grayson (2005) "examine the relative impact of service provider expertise, product performance, firm reputation, satisfaction, and similarity in influencing customer's perception of these dimensions of trust in a service provider. [...The results of their empirical study...] show that cognitive and affective dimensions of trust can be empirically distinguished and have both common and unique antecedents. The results also provide further clarification concerning the relationship between trust and sales effectiveness".

As regards the citation analysis - with sources as unit of analysis, 4 clusters have been identified (if considering minimum 3 documents of a source, and minimum one citation of a source, which led to a total of 29 sources) (Figure 7). The most representative citation sources in each cluster are: Journal of Business Research ( $1^{\text {st }}$ cluster - red) - with 13 links, 29 total link strength, and 8 documents; Journal of Business Ethics $\left(2^{\text {nd }}\right.$ cluster green) - with 19 links, 43 total link strength, and 19 documents; Corporate Reputation Review (3 $3^{\text {rd }}$ cluster - blue) - with 14 links, 35 total link strength, and 18 documents; and Academy of Management Journal (4 $4^{\text {th }}$ cluster - yellow) - 18 links, 93 total link strength, and 14 documents. 
Figure 7. "Media AND <<Corporate Reputation >> OR <<Firm Reputation >>" - citation sources map based on bibliographic data

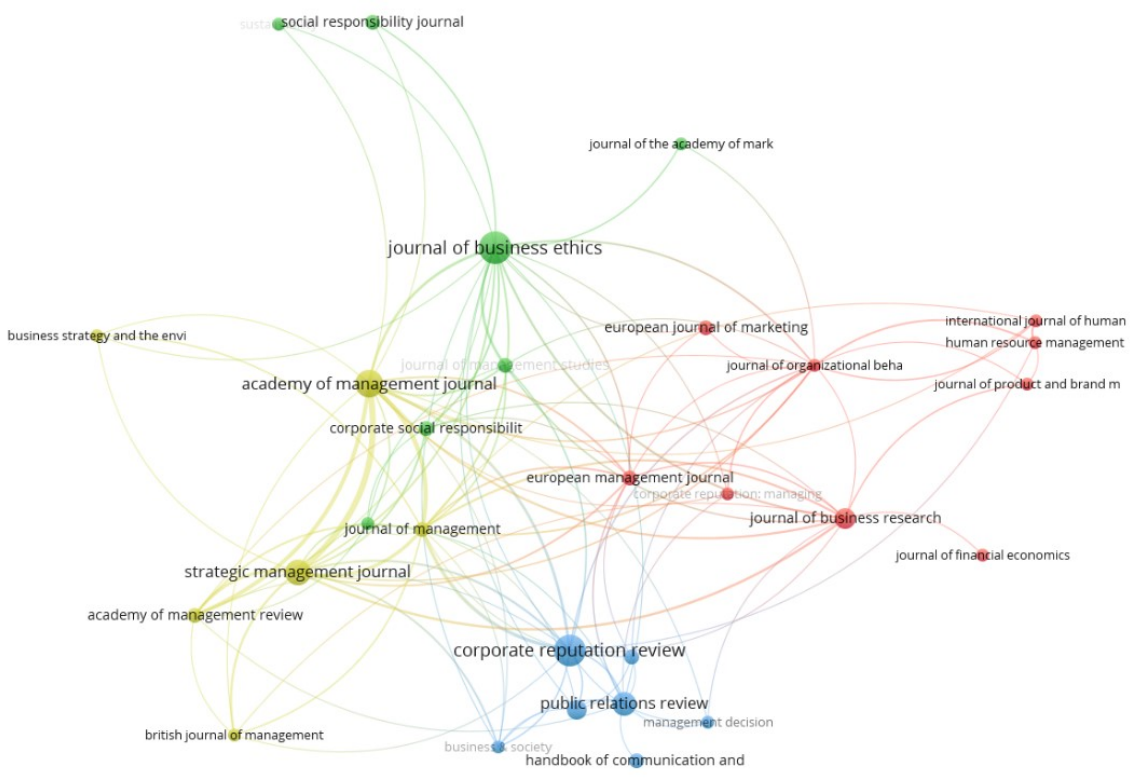

Source: authors - applying VOSviewer tool to WoS Core Collection data

The citation analysis - with authors as unit of analysis (if considering minimum three documents of an author and minimum one citation of an author) has led to 16 items, the largest set of connected items being six. The top three authors considering the total link strength are: Michael Pfarrer (5 documents), Violina Rindova (4 documents) and Timothy Pollock (3 documents) - the three being co-authors of an Academy of Management Journal study on "How status and celebrity influence strategic alliance formations by newly public firms" (Hubbard, et al., 2018).

If considering the bibliographic coupling - with documents as unit of analysis (and minimum one citation of a document), of the 363 documents meeting the threshold the top five documents (according to the total link strength) are listed in Table 5.

Table 5. "Media AND <<Corporate Reputation>> OR <<Firm Reputation >>" - Top 5 bibliographic coupling by documents

\begin{tabular}{|l|c|c|}
\hline Document & Citations & $\begin{array}{c}\text { Total link } \\
\text { strength }\end{array}$ \\
\hline $\begin{array}{l}\text { 1. } \\
\begin{array}{l}\text { Pollock, T. G., Lashley, K., Rindova, V. P., \& Han, J. H. (2019). Which of these } \\
\text { things are not like the others? Comparing the rational, emotional, and moral } \\
\text { aspects of reputation, status, celebrity, and stigma. Academy of Management } \\
\text { Annals, 13(2), 444-478. }\end{array}\end{array}$ & 4 \\
\hline $\begin{array}{l}\text { Ravasi, D., Rindova, V., Etter, M., \& Cornelissen, J. (2018). The formation of } \\
\text { organizational reputation. Academy of Management Annals, 12(2), 574-599. }\end{array}$ & 16 & 100 \\
\hline $\begin{array}{l}\text { Lange, D., Lee, P. M., \& Dai, Y. (2011). Organizational reputation: A } \\
\text { review. Journal of Management, 37(1), 153-184. }\end{array}$ & 328 & 99 \\
\hline $\begin{array}{l}\text { Ali, R., Lynch, R., Melewar, T. C., \& Jin, Z. (2015). The moderating influences on } \\
\text { the relationship of corporate reputation with its antecedents and consequences: } \\
\text { A meta-analytic review. Journal of Business Research, 68(5), 1105-1117. }\end{array}$ & 69 & 83 \\
\hline
\end{tabular}


5. Gatzert, N. (2015). The impact of corporate reputation and reputation damaging events on financial performance: Empirical evidence from the literature. European Management Journal, 33(6), 485-499.

Source: authors - applying VOSviewer tool to WoS Core Collection data

\section{Conclusions}

As strategic asset - determinant of competitive advantage and sustained competitiveness - corporate/firm reputation has a very distinctive feature that sets it apart: although reflection of (better, worse or not at all performed) reputation management at a company's level, it is rather a "representation" / a "perception" - built on a business's previous decisions and endeavors, but more precisely on the ways its different stakeholders have (both individually and collectively) interacted (acknowledged, internalized, resonated) with them - in a (sometimes unconscious) process highly mediated and moderated by the media (alongside both the power and the direction of the network effects it generates).

With more than eighty percent of the literature on the generic topic "media and <<corporate reputation>> or <<firm reputation>>" belonging to the current decade (yet not over: 2011-2019) on Web of Science Core Collection, the increasing interest on (and significance of) both corporate/firm reputation and media, as well as the strong (er with time) relationships between the two are indisputable. Beyond these easily noticeable facts, the in-depth analysis on the topic "media and $<<$ corporate reputation $>>$ or $<<$ firm reputation>>" - developed, using the VOSviewer bibliometric tool, by considering all the WoS records between 1992 and 2019 - revealed interesting results, with implications on both the literature and the practice in the field.

Business and Management are, by far, the best represented Wos Categories, followed by Economics and Communication; on the other hand, Business economics, Communication, and Social Sciences Other Topics make the top three Research Areas. If additionally considering: (a) that some of the results are placed in more than just one WoS category and/or research area; (b) reputation's high complexity (referring to and gathering a plethora of approaches, components, determinants, consequences, and dynamics) - it becomes clear that corporate/firm reputation (in a close, inseparable relationship with media) calls for an inter and/or trans disciplinary approach - as regards both the research (either theoretical or empirical) and the real-life organizational practice/management;

The analysis of the "term co-occurrence map based on text data" revealed four clusters, developed around the concepts of: "firm", "social medium", "environment", and "performance" - which (alone, and even more if taking into account their respective links within and across the different clusters) sketch the complex reference frame of reputation management and its processual character; these are not only backed, but also reinforced by the results of the analysis of the "keywords co-occurrence map based on bibliographic data", which came out with another four clusters, dominated by: "firm reputation", "corporate reputation", "reputation", and "consequences". Thus, the job of a company's reputation management is increasingly challenging, while forced to consider addressing (possible) reputation related issues in an integrative and anticipative manner; accordingly, in search of "performance" (either global or reputation related), the process of strategic 
alignment of the "firm" with its (internal and external) "environment" should: (a) properly monitor any relevant "social medium" able to influence "firm/corporate reputation" and (b) address any aspect of "reputation" in light of the (direct and propagated) "consequences" a decision might generate.

The five articles representing the "most cited document per cluster" in the analysis of the "citation documents map based on bibliographic data" disclosed a series of specific facets of corporate/firm reputation (in relation to media) - which contribute to both enlarging and deepening the field of research on corporate reputation and the practice of reputation management: (a) the familiarity - beliefs - impressions tryptic in conceptualizing reputation, the need for a multidimensional and dynamic approach of organizational reputation, on the one hand, and for a complex modeling of its antecedents and effects, on the other hand - if referring to the research on corporate reputation; (b) reputation versus celebrity, earnings surprise, investors' reactions, board diversity, corporate social responsibility, brand performance, industrial brand equity, customer satisfaction, trust, service relationships, sales effectiveness - in reference to the (ubiquitous and multilayered) reputation management practice.

With its emphasis on corporate/firm reputation and media, the paper shaped the broad theoretical backgrounds in anticipation of future research and empirical results to be revealed on a much more focused and applied/practical area, namely the reputation of the media in Romania. As media is not only a particular/distinctive industry, composed of businesses having (to manage) different reputations of their owns, but also an industry that has the capacity to significantly influence (through its businesses and by capitalizing on their own reputation) the reputation of other industries/businesses, the research on the reputation of the media is of high interest for a variety of (direct and indirect) stakeholders. Part of a bigger project developed by Media Reputation Lab - on the reputation of the media in Europe, the research on the reputation of the media in Romania will provide a description of the country's media reputation (media in general: radio, print, digital and television). For each one of these media, the valuation obtained by each of the reputational attributes (credibility, rigor, impartiality, willingness to rectify) by the informed population would be indicated.

\section{References}

Adeosun, L. P. K., \& Ganiyu, R. A. (2013). Corporate reputation as a strategic asset. International Journal of Business and Social Science, 4(2).

Ali, R., Lynch, R., Melewar, T. C., \& Jin, Z. (2015). The moderating influences on the relationship of corporate reputation with its antecedents and consequences: A meta-analytic review. Journal of Business Research, 68(5), 1105-1117.

Bear, S., Rahman, N., \& Post, C. (2010). The impact of board diversity and gender composition on corporate social responsibility and firm reputation. Journal of Business Ethics, 97(2), 207-221.

Cambridge Dictionary. Business English. Reputation. https://dictionary.cambridge.org/dictionary/english/reputation.

Chun, R. (2005). Corporate reputation: Meaning and measurement. International Journal of Management Reviews, 7(2), 91-109. 
Clive, C. (1997). Part I: Corporate Reputation as a Strategic Asset: Corporate Reputation and the Bottom Line. Corporate Reputation Review, 1(1), 19-23.

Duhé, S. C. (2009). Good management, sound finances, and social responsibility: Two decades of US corporate insider perspectives on reputation and the bottom line. Public Relations Review, 35(1), 77-78.

Fombrun, C., \& Van Riel, C. (1997). The reputational landscape. Corporate Reputation Review, 1-16.

Gatzert, N. (2015). The impact of corporate reputation and reputation damaging events on financial performance: Empirical evidence from the literature. European Management Journal, 33(6), 485-499.

Gomez-Trujillo, A. M., Velez-Ocampo, J., \& Gonzalez-Perez, M. A. (2020). A literature review on the causality between sustainability and corporate reputation: What goes first?. Management of Environmental Quality: An International Journal, 31(2), 406-430.

Hubbard, T. D., Pollock, T. G., Pfarrer, M. D., \& Rindova, V. P. (2018). Safe bets or hot hands? How status and celebrity influence strategic alliance formations by newly public firms. Academy of Management Journal, 61(5), 1976-1999.

Johnson, D., \& Grayson, K. (2005). Cognitive and affective trust in service relationships. Journal of Business Research, 58(4), 500-507.

Kapoor, K. K., Tamilmani, K., Rana, N. P., Patil, P., Dwivedi, Y. K., \& Nerur, S. (2018). Advances in social media research: Past, present and future. Information Systems Frontiers, 20(3), 531558.

Korn Ferry. WORTUNE World's Most Admired Companies. https://www.kornferry.com/insights/articles/fortune-worlds-most-admired-companies0.

Lai, C. S., Chiu, C. J., Yang, C. F., \& Pai, D. C. (2010). The effects of corporate social responsibility on brand performance: The mediating effect of industrial brand equity and corporate reputation. Journal of Business Ethics, 95(3), 457-469.

Lange, D., Lee, P. M., \& Dai, Y. (2011). Organizational reputation: A review. Journal of Management, 37(1), 153-184.

Li, S., Spry, L., \& Woodall, T. (2020). Corporate Social Responsibility and Corporate Reputation: A Bibliometric Analysis. International Journal of Industrial and Systems Engineering, 14(11), 1041-1045.

Osiyevskyy, O. (2017). Maximizing the strategic value of corporate reputation: a business model perspective. Strategy \& Leadership. 45(4), 24-32.

Pfarrer, M. D., Pollock, T. G., \& Rindova, V. P. (2010). A tale of two assets: The effects of firm reputation and celebrity on earnings surprises and investors' reactions. Academy of Management Journal, 53(5), 1131-1152.

Pollock, T. G., Lashley, K., Rindova, V. P., \& Han, J. H. (2019). Which of these things are not like the others? Comparing the rational, emotional, and moral aspects of reputation, status, celebrity, and stigma. Academy of Management Annals, 13(2), 444-478.

Ravasi, D., Rindova, V., Etter, M., \& Cornelissen, J. (2018). The formation of organizational reputation. Academy of Management Annals, 12(2), 574-599.

RepTrak (2020). 7 Ways to Quantify Reputation. https://www.reptrak.com/blog/7-ways-to-quantifyreputation/.

Rindova, V. P., \& Martins, L. L. (2012). Show me the money: A multidimensional perspective on reputation as an intangible asset. The Oxford Handbook of Corporate Reputation, 16-33.

Van Eck, N.J., \& Waltman. L. (2020). VOSviewer Manual 2020. https://www.vosviewer.com/.

Van Eck, N.J., \& Waltman, L. (2010). Software survey: VOSviewer, a computer program for bibliometric mapping. Scientometrics. 84. 523-538.

Veh, A., Göbel, M., \& Vogel, R. (2019). Corporate reputation in management research: a review of the literature and assessment of the concept. Business research, 12(2), 315-353. 